\title{
Study of Wildfire Environmental Conditions in Portugal with NOAA/NESDIS Satellite-Based Vegetation Health
} Index

\author{
Lourdes Bugalho ${ }^{1}$, Natália Camara ${ }^{1}$ and Felix Kogan ${ }^{2}$ \\ 1. Instituto Português do Mar e da Atmosfera, Rua C do Aeroporto, Lisboa 1749-077, Portugal \\ 2. NOAA/NESDIS Center for Satellite Applications and Research, MD 20276, USA
}

\begin{abstract}
Forest fires occur in Portugal every year during late spring, summer and fall. However, the beginning and end of the most severe season of forest fires are very variable, as is their intensity, the area and the number of occurrences. It is obvious, that vegetation stress and droughts are strongly linked to the occurrence of forest fires and burned area, showing a strong response to the drought. The vegetation health index (VHI), retrieved from the NOAA/NESDIS, shows good results in the detection of droughts, monitoring vegetation conditions in different countries. VHI is computed combining two terms: vegetation condition index (VCI), and temperature condition index (TCI) reflecting moisture and thermal vegetation conditions. The main objective of this study was to investigate the potential of VHI-method to monitor environmental conditions, favourable to forest fires in Portugal. Results of the study show that $88 \%$ of forest fires with burned area higher than 1,000 ha in a week, are well related with vegetation stress or drought conditions, detected with VHI-method. The results also show that the monitoring of the evolution of the VHI indexes is important for prevention burnt areas, especially in the spring, since it can indicate conditions for vegetation growth, which increases the fuel availability and the fire risk in the summer.
\end{abstract}

Key words: Forest fire risk, vegetation health index, vegetation stress, droughts.

\section{Introduction}

Forest fires are common phenomena in the Mediterranean region during the summer or in hot and dry spring/autumn conditions. It is one of the most severe natural disasters in Portugal. Most occurrences are in the summer months [1-3]. Portugal is one of the European countries most affected by wildfire. Monitoring weather wildfire risks taking into consideration also environment, become priority concern. Unfortunately, there are no regular observations of soil water content and the density of meteorological stations is not enough for this purpose. At present time, remote sensing of earth surface from operational satellites has become powerful tools to realize fire risk monitoring. Some satellite-based

Corresponding author: Lourdes Bugalho, Ph.D., research field: meteorological conditions for forest fire. vegetation indices, like normalized difference vegetation index (NDVI) and enhanced vegetation index (EVI), have been generally accepted and used to model forest fire danger $[4,5]$.

Fire favourable conditions and fire regime characteristics (burned area, frequency and severity) are mainly controlled by weather and climate. The relationship between drought conditions and forest fires is well documented and results show a clear increase in the burned area in response to medium or more severe drought situations [6]. Heat stress and drought determine forest productivity and fuel state and thus can affect fire intensity and severity.

This research investigated the possibility of using NOAA/NESDIS satellite-based vegetation health index (VHI) for monitoring wildfire environmental conditions in Portugal. During the last 20 years VHI-method was developed, tested, validated and 
applied globally and regionally. The VHI represents the moisture-thermal vegetation health and combines two indices: temperature condition index (TCI) and vegetation condition index (VCI). The VCI is a proxy of vegetation moisture conditions and TCI is a proxy of vegetation thermal conditions [7]. Climatic signals are removed, making use of climatic extremes and both indices shall reflect vegetation response to weather changes. These indices were successfully used for monitoring droughts, environmentally-based vegetation stress, fire risk, soil saturation and other associated natural hazards around the world [8,9]. Present study is focused on the relationship of VHI and its terms (VCI and TCI) on the most severe forest fires $(\geq 1,000$ ha) in Portugal over the period 2001-2017.

Drought events have a significant impact on the risk of forest fires, as heat stress and precipitation deficit reduce soil and fuel moisture, leading to easy ignition and spread of forest fires $[6,10]$.

The number of occurrences of big forest fires (burning areas of more than 1,000 ha per week) was related with the evolution of VHI-indices for period 2001-2017.

\section{VHI and Droughts}

The NOAA/NESDIS VHI-method is based on the properties of green vegetation to reflect sunlight and emit absorbed solar radiation and uses NDVI or the brightness temperature (BT). The pigmentation of plant leaves, chlorophyll, strongly absorbs light in a visible part (VIS) of the spectrum $(0.4-0.7 \mu \mathrm{m})$ during the photosynthesis process. On the other hand, the cell structure of leaves strongly reflects light in part of the near infrared (NIR) spectrum. Healthy and no water-stressed vegetation has a reduced VIS and an increased NIR, resulting in a higher NDVI. The healthy vegetation absorbs and emits less thermal infrared radiation (IR), resulting in lower BT and cooler coverage. Drought depresses green vegetation, decreases vigour and makes canopy warm due to an increase on VIS (after chlorophyll depletion), decrease on NIR (after a drop in water content), decreasing NDVI and showing an increase in thermal values of IR and BT [11, 12].

NDVI and BT indices reflect three environmental signals: ecosystem, climate and real-time weather. In order to estimate the effects of the actual weather conditions, the NDVI and BT indexes were normalized by their climatology. The computation of NDVI and BT climatologically values followed by three biophysical laws: the Leibig's Low of Minimum, the Shelford's Low of Tolerance and the Principal of Carrying Capacity [12-14].

NDVI and BT values were expressed as deviations from climatologic extremes and became:

- VCI - a proxy of vegetation moisture conditions:

$$
V C I=100 * \frac{\left(N D V I-N D V I_{\min }\right)}{\left(N D V I_{\max }-N D V I_{\min }\right)}
$$

- TCI-a proxy of the thermal conditions of vegetation:

$$
T C I=100 * \frac{\left(B T_{\max }-B T\right)}{\left(B T_{\max }-B T_{\min }\right)}
$$

- VHI-a combination of the first two:

$$
V H I=\alpha * V C I+(1-\alpha) T C I, \alpha=0.5
$$

$B T_{\max }, N D V I_{\max }, B T_{\min }, N D V I_{\min }$ represent respectively, the maximum and minimum values of $B T$ and NDVI for each week, during the observation period of 37 years (1981-2017). They represent the extreme climatologic thresholds of weekly values of $N D V I$ and $B T$ variations, due to the change in time. Differences $\left(N D V I_{\max }-N D V I_{\min }\right)$ and $\left(B T_{\max }-B T_{\min }\right)$ reflect the level of climate variability.

Thus, expressions for VCI and TCI are showing the percentage of deviation of the NDVI and BT values of extreme climatologic thresholds reflecting vegetation stress due to lack of soil water and excessive heating.

Each index (VCI, TCI and VHI) varies from zero, in case of extreme stress of vegetation, up to 100 , in case of optimal conditions for vegetation. For many agricultural crops, a reduction of VHI-indices below 40 is correlated with a reduction of crop yield below 
long-term mean or trend [15-17]. Therefore, the value of indices below 40 is accepted as the beginning of a drought [7]. Drought intensifies when the indices decrease from 40 (mild drought) to zero (exceptional drought). The criterion for drought intensity was established based on crop yield correlation with VHI-indices [15, 16, 18]. The VHI has been validated in 29 countries and is used globally since the 2000s, approximating vegetation condition [16] VHI-based drought assessments, include drought area, intensity, duration and origination (either from moisture or thermal or both), crop and pasture losses, wildfire risk, and drastic changes in conditions over time. VHI data are global and are weekly composites.

\section{Materials and Methods}

VHI, VCI and TCI-indices 4-km data, were weekly collected, for Portugal continental for period 2000-2017. From collected data using VHI-method and for each of 18 districts (administrative areas) of Portugal, were computed: (i) weekly average values of VHI-indices, averaging the values of the VHI-indices within the district area and (ii) weekly percentage of area of districts with droughts, detected with VHI-indices. Condition of drought was considered whenever the value of VHI was less than $40 \%$.

Fire information (burned areas and number of forest fires occurrences) is from of the Portuguese Institute of Nature Conservation and Forests responsibility, providing daily fire information, for each of the 18 districts of Portugal. Data were obtained from January 2001 to December 2017. Values were accumulated for periods of $7 \mathrm{~d}$ (weekly distributed), obtaining burnt areas and number of fire occurrence for each district.

Processed VHI data were compared with data of wild forest fires (number of fires occurrences and burned areas). The goal was to investigate how vegetation conditions and droughts, detected using VHI-method, match occurred fires.

A relationship between natural causes and possible consequences is never simple due to the human and socioeconomic impact.

VHI-indices and weekly fire data for the period 2001-2017, were used to try establishing a relationship between environmental conditions and fire occurrence. To investigate the possibility of using VHI-method for monitoring wildfires conditions in Portugal, a correspondence of big fires (weekly burnt area $\geq 1,000 \mathrm{ha}$ ) with environmental conditions was analyzed. VHI-method was used to detect favourable conditions to big wildfires occurrences: (i) vegetation stress resulting from lack of soil water ( $\mathrm{VCI}<40.0$ );

(ii) vegetation stress resulting from leaves overheating (TCI < 40.0); (iii) percentage of area with droughts, exceeding $20 \%$ of district. Statistical analyses were also performed in order to relate, the percentile of the district's drought percentage and the number of big forest fires.

\section{Environmental Conditions and Fire Occurrence in Portugal}

Mediterranean climate peculiarities create very favourable conditions for wildfire occurrence. Droughts are part of climate of Portugal, with a hot and dry summer. The deep, severe and extreme droughts always start with local droughts, which can transform later in a severe. In fact, in Portugal local droughts occur every year, especially in the summer and can be detected using the VHI-method (Fig. 1).

The particularity of climate in Portugal is a hot summer with low amount of precipitation. According to "Iberian Climate Atlas" [19], in July and August climate normal values of precipitation (1971-2000) are less than $30 \mathrm{~mm}$ for north of Portugal and less or about $10 \mathrm{~mm}$ for centre and south. By this reason, July-August is the period of fire activity ("fire season window"), independently of soil moisture conditions and drought occurrence.

In Portugal climate annual precipitation regime has two maximums: one in the late autumn and winter months and the other, in the spring (Fig. 2).

Spring precipitation is important for vegetation 


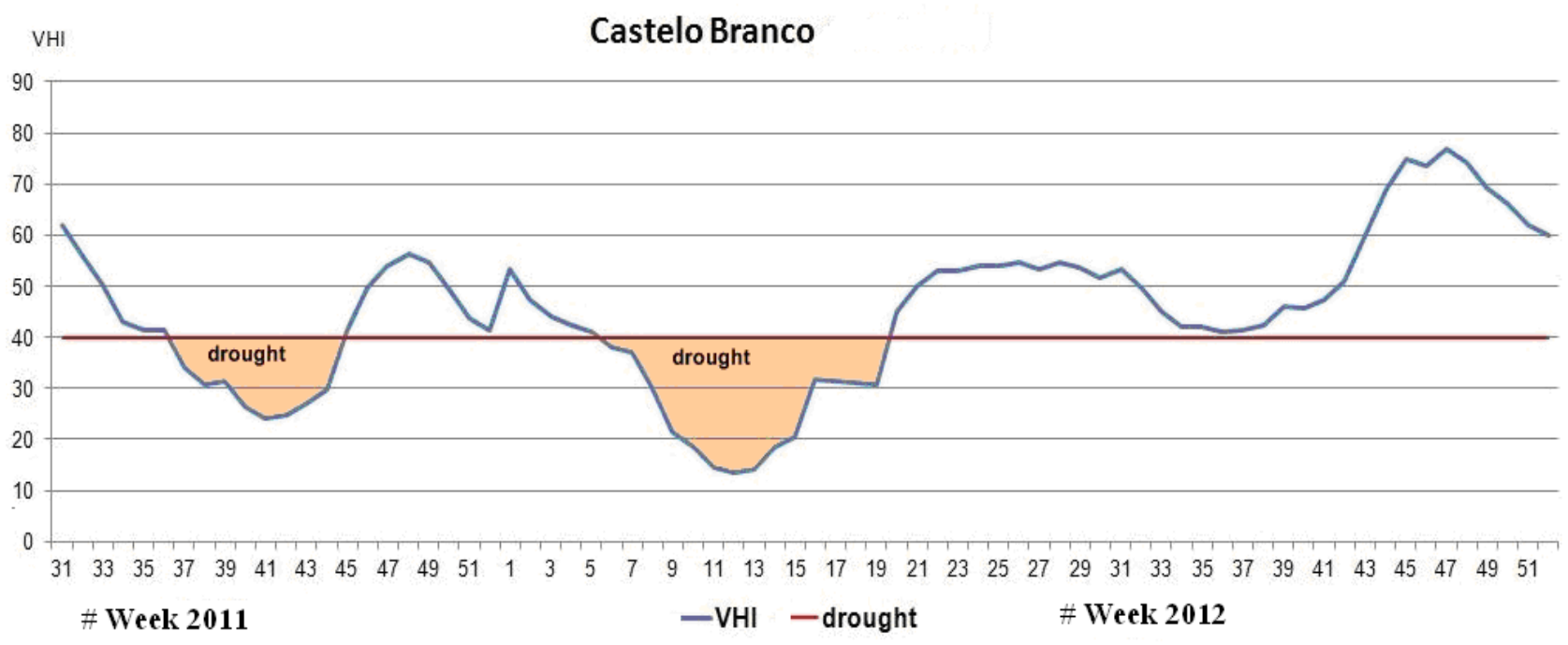

Fig. 1 Local droughts, at the Castelo Branco Weather Station, detected by the vegetation health index (VHI) method (with VHI values below 40\%).

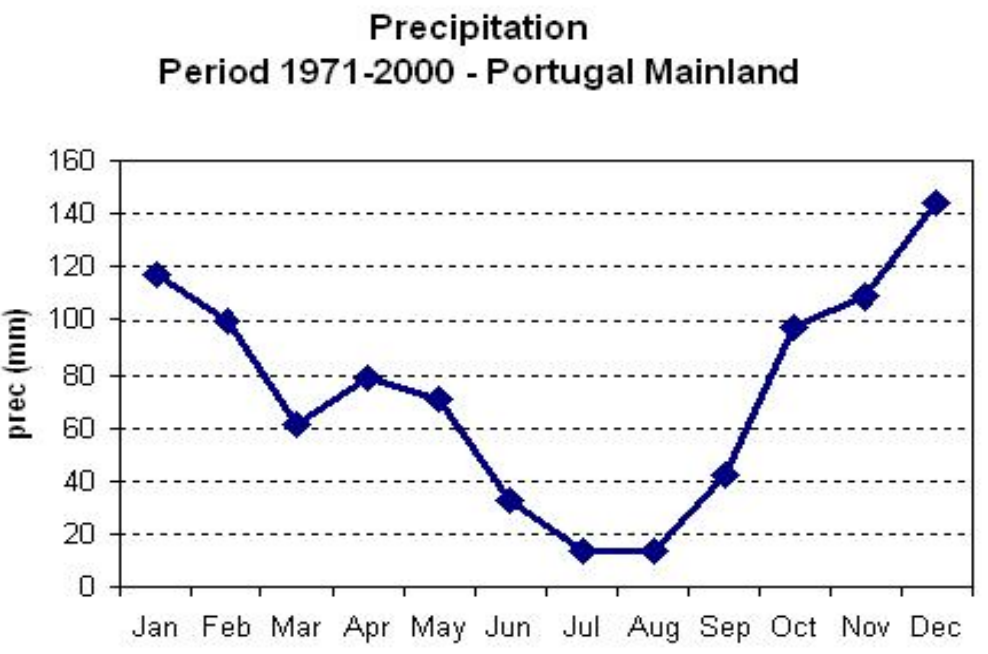

Fig. 2 Precipitation climate normal observed 1971-2000.

phenological stages: growing and flowering. During this period, evapotranspiration becomes high and vegetation grows and develops, taking deposited water from the soil. In early summer, water is a vital plant need too, but precipitation becomes very small in conditions of high temperature (climate), making soil moisture and groundwater reserves the only source of the water. Therefore, plant stress is not rare in the Mediterranean summer. For surviving, plants use different mechanism of adaptation, one of which is transpiration cooling [20]. This mechanism, representing a natural plant adaptation against heat stress, promotes soil draining too. Lack of the soil water to support plant transpiration and overheating plant leaves, has impact on a change in the processes of metabolism, photosynthesis in leaves and branches, resulting in scorching, abscission and senescence. The increase in fine fuel and flammable conditions is inevitable. This way, Mediterranean climate and vegetation contributes to dry soil conditions and to fire occurrence [21]. In spring time, insufficient amount of precipitation, elevated temperatures or droughts, lead to an early start of the forest fires season (Fig. 3). 
a)

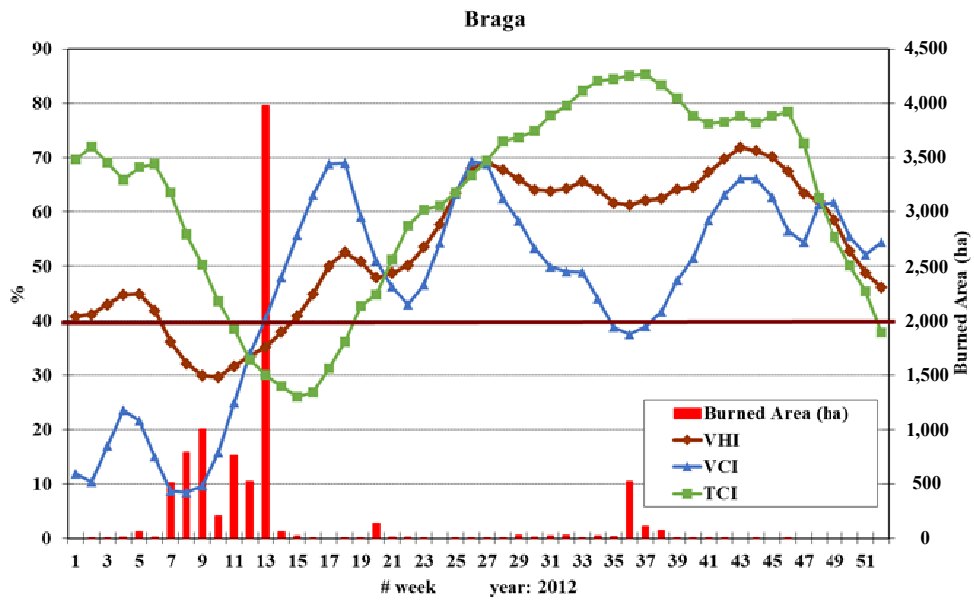

b)

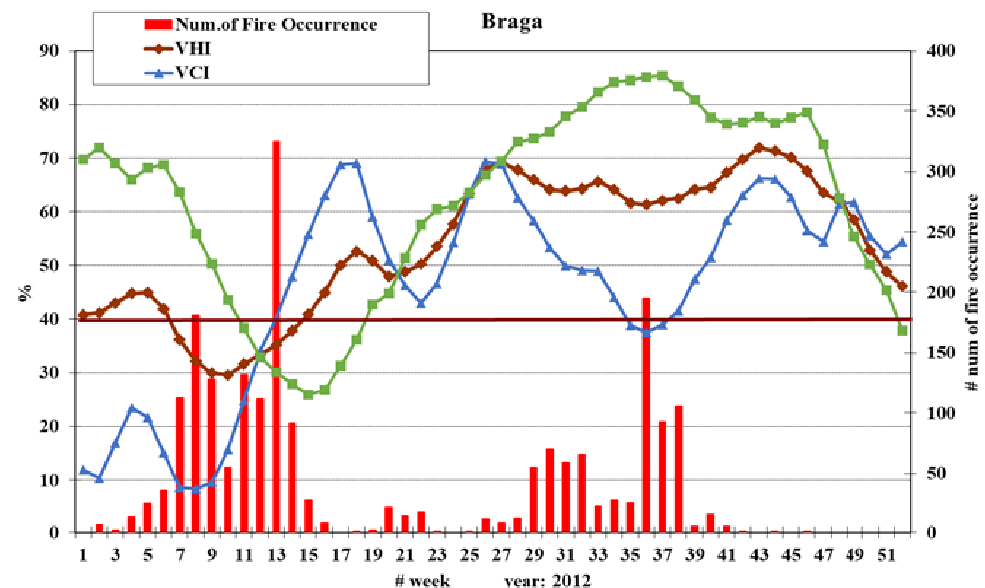

c)

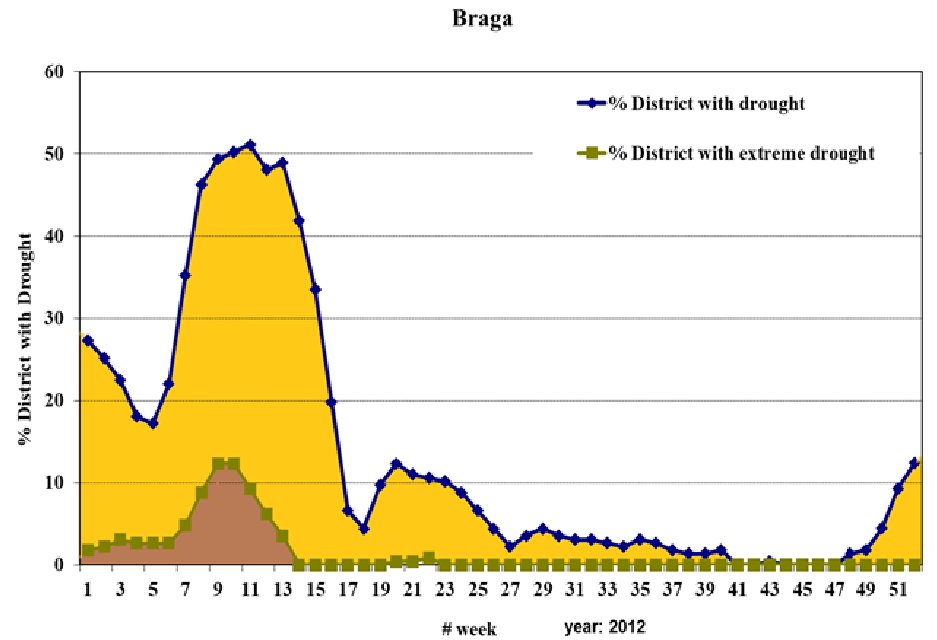

Fig. 3 Drought at the Braga district, detected by VHI-method, and fire occurrence in spring 2012, with (a) burned area (ha), (b) number of wildfire and (c) percentage of district with drought. 


\section{Results and Discussion}

Fire conditions are controlled by climate and weather, both linked to the possibility of fuel burning: the fuel moisture (direct effect) and the fuel structure (indirect effect). Fuel structure refers to the amount of existing fuel and, fuel moisture determines the possibility of burning this existing fuel. It is well known that fuel flammability and fire hazard increase in case of dry weather conditions and warm years [22-24]. Fire activity may also increase when moist conditions precede the fire season, creating potential fuel [21, 25-27]. In conditions of Mediterranean climate, with dry weather conditions, hot summer, vegetation stress due to the lack of soil water or to the excessive heating of leaves, it can lead to increasing fine fuel and, consequently flammable conditions [21].

By these reasons it was compared the correspondence of big fires (burned week area $\geq 1,000$ ha) to the next conditions: (i) vegetation stress caused by lack of soil water (VCI < 40.0); (ii) vegetation stress caused by leaves overheating (TCI $<40.0$ ); (iii) percentage of district area, considered as affected by droughts, detected by VHI-method, when exceeding $20 \%$ of the total area of the district. This study was applied to 13 of the 18 districts. The five remained districts have, in general, smaller forest areas and lower burned areas. The results, obtained for the studied districts (Table 1), show that $88 \%$ of the large fires have relation with, at least, one of the stress conditions mentioned above.

More detailed statistical analysis has showed that for all districts there is a relation between the highest values of the percentile of the district's drought percentage and the number of big forest fires (Fig. 4). It's clear that higher percentile of district drought corresponds to higher number of big fires

To understand which pattern in VHI behavior leads to big fires, the common analysis of VHI-indices dynamics and cases of wildfires were performed. It was observed that one of such patterns is the case, when in spring conditions of low values of TCI and high value of VCI lead to decreasing of VCI (Fig. 5), hydric stress and sometimes to the droughts later.

Early beginnings of fire season and big wildfires in summer are associated with this pattern frequently. Condition TCI $>60$ is determined as a plant's temperature comfort zone. Plant overheating reduces TCI: condition $40<\mathrm{TCI}<60$ corresponds to uncomfortable thermal conditions and condition TCI $<40$ corresponds to thermal stress. Impact of temperature stress is different for different phenological stages of plant. During active growth, all plants are highly sensitive to temperature stress [28]. So, in spring, in conditions overheating $(\mathrm{TCI}<60$ ) vegetation secures comfortable conditions for growing with increasing of transpiration. Intensive transpiration leads to reducing soil water content, earlier soil draining, lower water table and, as a result, hydric vegetation stress $(\mathrm{VCI}<40$ ), that can lead to the drought $(\mathrm{VHI}<40)$.

In summer temperature stress itself can result in increasing of flammability, drying fine fuel [21].

Table 1 Wildfires number and burned area by district for period 2001-2017.

\begin{tabular}{lll}
\hline District & A & B \\
\hline Aveiro & 12 & 11 \\
Braga & 38 & 37 \\
Bragança & 35 & 29 \\
Castelo Branco & 30 & 28 \\
Coimbra & 22 & 14 \\
Faro & 11 & 8 \\
\hline
\end{tabular}


(Table 1 continued)

\begin{tabular}{lll}
\hline District & A & B \\
\hline Guarda & 53 & 46 \\
Leiria & 14 & 13 \\
Porto & 27 & 25 \\
Santarém & 23 & 20 \\
Viana do Castelo & 29 & 24 \\
Vila Real & 48 & 45 \\
Viseu & 52 & 47 \\
\hline Total & 394 & 347 \\
\hline
\end{tabular}

A - number of wildfires with weekly burned area $\geq 1,000$ ha for the period 2001 to 2017 ;

B - number of wildfires, which correspond to drought or conditions of vegetation stress, for the period 2001 to 2017.
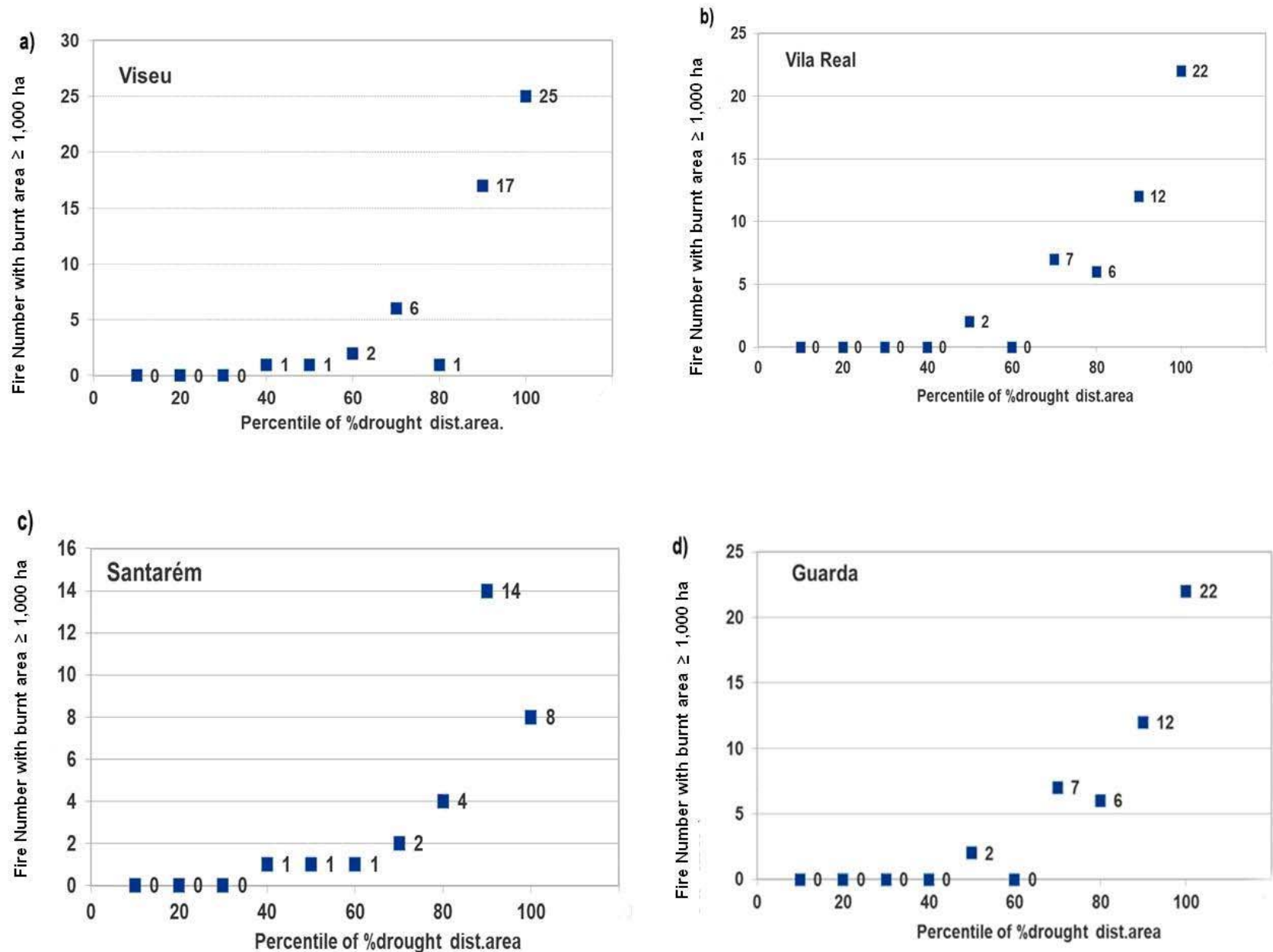

Fig. 4 Plot representing the number of forest fires, with burned weekly area $\geq 1,000$ ha, observed for each class of drought percentage of the district, based on percentiles, as example plot the results for the districts: (a) Viseu, (b) Vila Real, (c) Santarem, (d) Guarda. 
a)

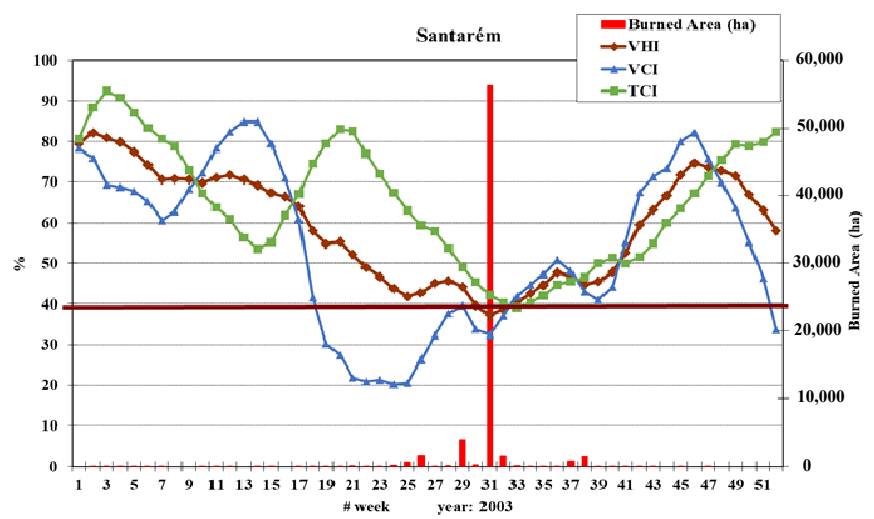

b)

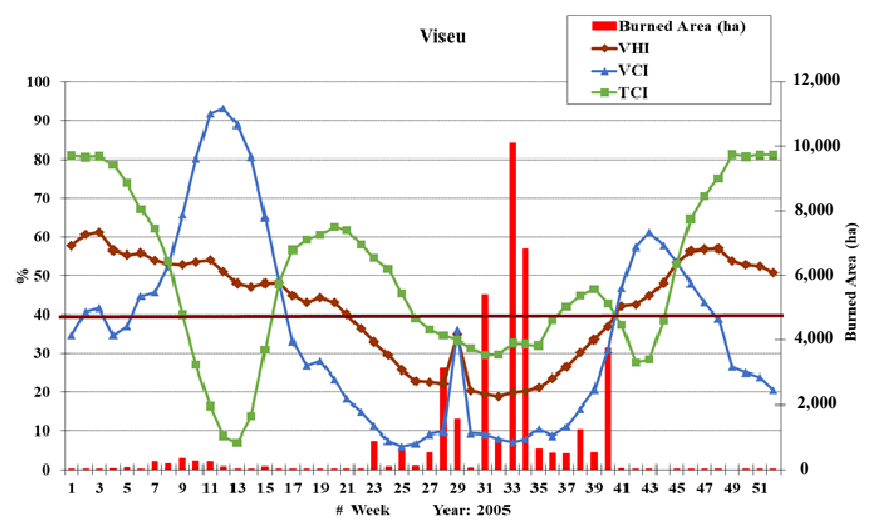

c)

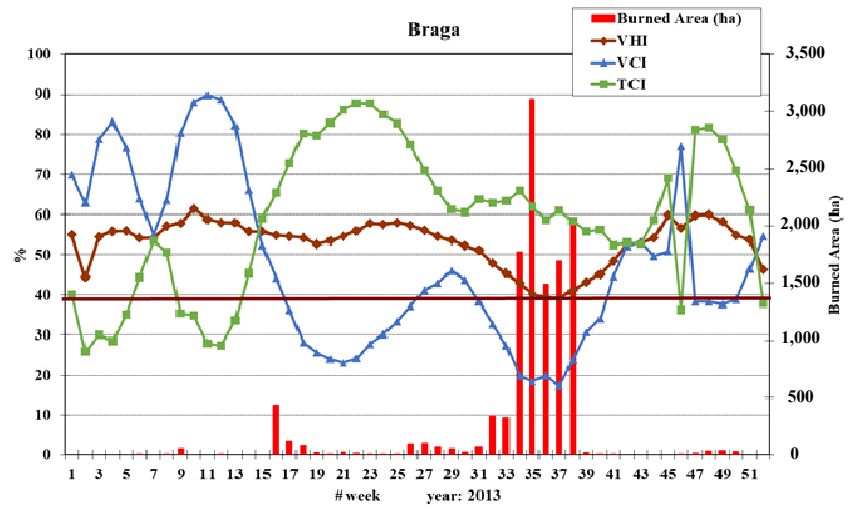

Fig. 5 The weekly evolution of the district's average VHI-indices and the district total burned area for (a) 2003 (Santarem), (b) 2005 (Viseu) and (c) 2013 (Braga), as an example of years of large burnt areas.

\section{Conclusions}

Recent studies show that the inter-annual variability of the burned areas may be fairly well reproduced by statistical models based only on meteorological variables due to the anthropogenic influence on the fires despite being strongly controlled by summer weather conditions.

In spite of this, the dynamics of VHI-indices, show good relation both to the burned areas and to the 
number of events of forest fires. Graphs with the representation of these relations for some districts are shown, as examples, in Figs. 3 and 5.

The statistical results have demonstrated that for 13 of the 18 districts of Portugal with larger burned areas, $88 \%$ of big fires have relation with at least one of next conditions, detected with VHI-method:

- vegetation stress because of lack of soil water $(\mathrm{VCI}<40.0)$;

- vegetation stress because of the leaves overheating $(\mathrm{TCI}<40.0)$;

- percentage of drought by district exceeded $20 \%$.

It means that preferably the large forest fires occur if the district has a percentage of drought are equal to or greater than $20 \%$.

The results also show the relationship between the number of weeks with burned areas exceeding 1,000 ha and the percentile of the percentage of the district in drought: percentile above $60^{\text {th }}$ percentile of the percentage of district in drought correspond to higher number of big wildfires.

The analyse of VHI indices evolution and their relationship with forest fires showed the possibility in determining the VHI patterns that could be used as indicators of probability of large fires in Portugal.

One of the typical cases was observed frequently in the spring in the years with large forest fires. In this pattern the TCI shows low value, indicating thermal stress, and VCI has high value, indicating good vegetation growth in spring. Usually these conditions lead to large production of fine fuel that dries in summer favoring large fires.

\section{References}

[1] Plana, E., Font, M., Serra, M., Borràs, M., and Vilalta, O. 2016. Fire and Forest Fires in the Mediterranean: A Relationship Story between Forest and Society. Five Myths and Realities to Learn More. eFIREcom project. CTFC editions, 36. http://efirecom.ctfc.cat/docs/revistaefirecom_en.pdf.

[2] San-Miguel-Ayanz, J., Durrant, T., Boca, R., Libertà, G., Boccacci, F., Di Leo, M., López Pérez, J., and Schulte, E. Forest Fires in Europe, Middle East and North Africa
2015, EUR 28158 EN, 122. https://doi.org/10.2788/914; http://effis.jrc.ec.europa.eu/media/cms_page_media/40/F orest_fires_in_Europe_Middle_east_and_North_Africa_2 015_final_pdf_JkX4Y13.pdf.

[3] Camia, A., and Amatulli, G. 2009. "Weather Factors and Fire Danger in the Mediterranean." In Earth Observation of Wildland Fires in Mediterranean Ecosystems. Berlin, Heidelberg: Springer, 71-82.

[4] Illera, P., Fernández, A., and Delgado, J. A. 2007. "Temporal Evolution of the NDVI as an Indicator of Forest Fire Danger." International Journal of Remote Sensing 17 (6): 1093-105.

[5] Bisquert, M., Sánchez, J. M., and Caselles, V. 2014. "Modeling Fire Danger in Galicia and Asturias (Spain) from MODIS Images." Remote Sens. 6: 540-54.

[6] Littell, J. S., Peterson, D. L., Riley, K. L., Liu, Y. Q., and Luce, C. H. 2016. "A Review of the Relationships between Drought and Forest Fire in the United States." Global Change Biology 22 (7): 2353-69. doi:10.1111/gcb.13275.

[7] Kogan, F. 1997. "Global Drought Watch from Space." Bulletin American Meteorological Society 78: 621-36.

[8] Kogan, F. 2018. Remote Sensing for Food Security Springer International Publishing, doi: 10.1007/978-3-319-96256-6.

[9] Rahman, A., Kogan, F., Roytman, L., Goldberg, M., and Guo, W. 2011. "Modelling and Prediction of Malaria Vector Distribution in Bangladesh from Remote-Sensing Data." International Journal of Remote Sensing 32 (5): 1233-51. doi:10.1080/01431160903527447.

[10] Jurdao, S., Chuvieco, E., and Arevalillo, J. M. 2012. "Modelling Fire Ignition Probability from Satellite Estimates of Live Fuel Moisture Content." Fire Ecology 8 (1): 77-97.

[11] Cracknell, A. P. 1997. The Advanced Very High Resolution Radiometer (AVHRR). London: Taylor \& Francis, 534.

[12] Kogan, F. N. 2001. "Operational Space Technology for Global Vegetation Assessment." Bulletin of the American Meteorological Society 82: 1949-64.

[13] Kogan, F. N. 1995. "Droughts of the Late 1980s in the United States as Derived from NOAA Polar-Orbiting Satellite Data." Bulletin of the American Meteorological Society 76 (5): 655-67.

[14] Kogan, F., Gitelson, A., Zakarin, E., and Lebed, E. 2003. "AVHRR-Based Spectral Vegetation Index for Quantitative Assessment of Vegetation State and Productivity: Calibration and Validation." Photogrammetric Engineering \& Remote Sensing 69 (8): 899-906. https://digitalcommons.unl.edu/natrespapers/278.

[15] Kogan F., Gitelson, A., Zakarin, E., and Lebed, E. 1998. "Using AVHRR Data for Quantitative Estimation of 


\section{Satellite-Based Vegetation Health Index}

Vegetation Conditions: Calibration and Validation." Adv. Space Res. 22 (5): 673-6.

[16] Kogan, F., and Guo, W. 2014. "Early Twenty-First-Century Droughts during the Warmest Climate." Geomatics, Natural Hazards and Risk 7 (1): 127-37. http://dx.doi.org/10.1080/19475705.2013.878399.

[17] Kogan, F., and Guo, W. 2015. "2006-2015 Mega-Drought in the Western USA and Its Monitoring from Space Data." Geomatic, Natural Hazards and Risk 6 (8): 651-68. doi:10/1080/19475705.2015.1079265.

[18] Hayas, M. J., and Decker, W. L. 1996. "Using NOAA AVHRR Data to Estimate Maize Production in the United States Corn Belt." International Journal of Remote Sensing 17: 3189-200.

[19] Iberian Climate Atlas (1971-2000). 2011. Portuguese Institute of Meteorology. http://www.ipma.pt/resources.www/docs/publicacoes.site /atlas_clima_iberico.pdf. (in Portuguese)

[20] Fitter, A. H., and Hay, R. K. M. 2002. Environmental Physiology of Plants, 3rd ed. London, UK: Academic Press.

[21] Pausas, J. G. 2004. "Changes in Fire and Climate in the Eastern Iberian Peninsula (Mediterranean Basin)." Climatic Change 63: 337-50.

[22] Flannigan, M. D., and Harrington, J. B. 1988. "A Study of the Relation of Meteorological Variables to Monthly
Provincial Area Burned by Wildfire in Canada (1953-80).” Journal of Applied Meteorology 27: 441-52.

[23] Piñol, J., Terradas, J., and Lloret, F. 1998. "Climate Warming, Wildfire Hazard, and Wildfire Occurrence in Coastal Eastern Spain." Climatic Change 38: 345-57.

[24] Founda, D., and Giannakopoulos, C. 2009. "The Exceptionally Hot Summer of 2007 in Athens, Greece-A Typical Summer in the Future Climate?" Global and Planetary Change 67: 227-36.

[25] Keeley, J. E. 2004. "Impact of Antecedent Climate on Fire Regimes in Coastal California." International Journal of Wildland Fire 13: 173-82.

[26] Littell, J. S., McKenzie, D., Peterson, D. L., and Westerling, A. L. 2009. "Climate and Wildfire Area Burned in Western US Ecoprovinces, 1916-2003." Ecological Applications 19: 1003-21.

[27] Archibald, S., Nickless, A., Govender, N., Scholes, R. J., and Lehsten, V. 2010. "Climate and the Inter-annual Variability of Fire in Southern Africa: A Meta-analysis Using Long-Term Field Data and Satellite-Derived Burnt Area Data." Global Ecology and Biogeography 19: 794-809.

[28] Hasanuzzaman, M., Nahar, K., Alam, M. M., Roychowdhury, R., and Fujita, M. 2013. "Physiological, Biochemical, and Molecular Mechanisms of Heat Stress Tolerance in Plants." Int. J. Mol. Sci. 14: 9643-84. 